\title{
Pharmacokinetics of oxycodone/naloxone and its metabolites in patients with end-stage renal disease during and between haemodialysis sessions
}

\author{
Anne Leuppi-Taegtmeyer ${ }^{1}$, Urs Duthaler ${ }^{1}$, Felix Hammann ${ }^{1}$, Yasmin Schmid ${ }^{1}$, Michael Dickenmann ${ }^{2,3}$, \\ Patricia Amico $^{2,3}$, Andreas W. Jehle ${ }^{2,3}$, Stefan Kalbermatter ${ }^{4}$, Christoph Lenherr ${ }^{4}$, \\ Henriette E. Meyer zu Schwabedissen ${ }^{5}$, Manuel Haschke ${ }^{6}$, Matthias E. Liechti ${ }^{1}$ and Stephan Krähenbühl ${ }^{1}$ \\ ${ }^{1}$ Division of Clinical Pharmacology and Toxicology, Department of Biomedicine and Department of Clinical Research, University Hospital \\ Basel, University of Basel, Basel, Switzerland, ${ }^{2}$ Transplantation Immunology and Nephrology, University Hospital Basel, Basel, Switzerland, \\ ${ }^{3}$ Department of Medicine, Hirslanden Klinik St. Anna, Lucerne, Switzerland, ${ }^{4}$ Nephrology and Dialysis, Medical University Clinic and \\ Kantonsspital Baselland, Liestal, Switzerland, ${ }^{5}$ Department of Pharmaceutical Sciences, University of Basel, Basel, Switzerland and ${ }^{6}$ Clinical \\ Pharmacology and Toxicology, Department of General Internal Medicine, Inselspital, Bern University Hospital, University of Bern, Bern, \\ Switzerland
}

Correspondence and offprint requests to: Matthias E. Liechti; E-mail: matthias.liechti@usb.ch

\section{ABSTRACT}

Background. The pharmacokinetics of oxycodone in patients with end-stage renal disease (ESRD) requiring haemodialysis are largely unknown. Therefore, we investigated the pharmacokinetics of oxycodone/naloxone prolonged release and their metabolites in patients with ESRD during and between haemodialysis sessions.

Methods. Single doses of oxycodone/naloxone (5/2.5 or 10/ $5 \mathrm{mg}$ ) were administered in nine patients with ESRD using a cross-over design on the day of dialysis and on a day between dialysis sessions. Plasma, dialysate and urine concentrations of oxycodone, naloxone and their metabolites were determined up to $48 \mathrm{~h}$ post-dosing using a liquid chromatography-tandem mass spectrometry system.

Results. Haemodialysis performed 6-10 h after dosing removed $\sim 10 \%$ of the administered dose of oxycodone predominantly as unconjugated oxycodone and noroxycodone or conjugated oxymorphone and noroxymorphone. The haemodialysis clearance of oxycodone based on its recovery in dialysate was (mean \pm SD) $8.4 \pm 2.1 \mathrm{~L} / \mathrm{h}$. The geometric mean (coefficient of variation) plasma elimination half-life of oxycodone during the 4-h haemodialysis period was $3.9 \mathrm{~h}$ (39\%) which was significantly shorter than the $5.7 \mathrm{~h}(22 \%)$ without haemodialysis. Plasma levels of the active metabolite oxymorphone in its unconjugated form were very low.

Conclusions. Oxycodone is removed during haemodialysis. The pharmacokinetics including the relatively short half-life of oxycodone in patients with ESRD with or without haemodialysis and the absence of unconjugated active metabolites indicate that oxycodone can be used at usual doses in patients requiring dialysis.
Keywords: haemodialysis, naloxone, oxycodone, pharmacokinetics, renal failure

\section{INTRODUCTION}

The oxycodone/naloxone prolonged release (PR) combination is licensed in Switzerland for the treatment of moderate to severe pain that cannot be adequately managed with non-opioid analgesics. The opioid antagonist component naloxone is for the treatment and prevention of opioid-induced constipation $[1-3]$. Opioids are frequently prescribed in patients with advanced illnesses who may also have end-stage renal disease (ESRD) requiring haemodialysis [4]. The pharmacokinetics of oxycodone/naloxone PR in such patients are largely unknown.

Oxycodone has a high oral bioavailability of $50-87 \%[5,6]$. It is metabolized mainly via CYP3A4-mediated N-demethylation to noroxycodone and via CYP2D6-meidated O-demethylation to oxymorphone $[7,8]$. Noroxycodone is considered to be the main metabolite of oxycodone [5, 7-9]. It is pharmacologically active at the $\mu$-opioid receptor, but 5 -fold less potent than oxycodone [10]. Oxymorphone, on the other hand, is 8-fold more potent than oxycodone [10-12]. The formation of oxymorphone is dependent on the function of polymorphic CYP2D6 $[8,13,14]$. Both metabolites are further metabolized to noroxymorphone, which is only weakly active [10]. Oxycodone and all its metabolites are ultimately glucuronidated [15]. Whether the glucuronide metabolites are active is unknown. Many studies have investigated pharmacokinetics of oxycodone and its metabolites in subjects with normal renal function $[5,6,13,16-19]$, including the influence of drug-drug 
interactions and CYP2D6 polymorphisms [8, 13, 17, 20-26]. However, there is only limited information in patients with ESRD $[19,27,28]$. In a previous study, pharmacokinetic profiles were assessed up to $24 \mathrm{~h}$ after administration of intravenous oxycodone $(0.07 \mathrm{mg} / \mathrm{kg})$ in 10 patients with ESRD during general anaesthesia for renal transplantation surgery and compared with 10 patients with normal renal function undergoing general surgery [19]. The plasma elimination half-life of oxycodone was prolonged and highly variable (mean \pm SD: $7 \pm 7 \mathrm{~h}$ ) compared with that in patients with normal renal function $(3.4 \pm 1 \mathrm{~h})$ [19]. Possible accumulation of oxycodone was reported in a single haemodialysis patient [28], while safe use and removal by haemodialysis was reported in another case [27]. Systematic data on the pharmacokinetics of oxycodone and its metabolites in patients with ESRD not currently undergoing surgery or during dialysis itself are, however, completely lacking.

Our primary goal was to describe the pharmacokinetics of oxycodone, naloxone, their metabolites oxymorphone, noroxycodone, noroxymorphone and respective glucuronides after a single dose of oxycodone/naloxone PR in patients with ESRD during and between intermittent haemodialysis sessions.

\section{MATERIALS AND METHODS}

\section{Study design}

Single doses of oral oxycodone/naloxone PR (5/2.5 or 10 / $5 \mathrm{mg}$ ) were administered in patients with ESRD undergoing intermittent haemodialysis using a cross-over design with two randomly assigned conditions (with and without haemodialysis). The washout periods between the test days were at least 7 days. The study was approved by the local Ethics Committee and the Swiss Agency for Therapeutic Products (Swissmedic), and conducted in accordance with the Declaration of Helsinki. All subjects provided written consent before participating in the study, and they were paid for their participation. The study was registered at EudraCT (EudraCT no: 2013-005022-30) and performed between May 2014 and March 2017.

\section{Patient selection}

Male and female outpatients with ESRD requiring haemodialysis aged between 18 and 80 years were recruited from the dialysis centres of the University Hospital Basel and Medical University Clinic, Kantonsspital Baselland, Switzerland. Exclusion criteria included: body mass index $<18$ or $>40 \mathrm{~kg} /$ $\mathrm{m}^{2}$; body weight $<50 \mathrm{~kg}$; pregnant or lactating women; severe cardiovascular disease (myocardial infarction within the last 6 months, New York Heart Association class III and IV); haematological disease; acute or severe bronchial asthma or hypercapnia; respiratory depression; paralytic ileus; neoplasia; moderate to severe hepatic impairment; severe deviations from normal values in the routine laboratory tests not explained by the ESRD; major abnormalities in physical examination (in particular: systolic blood pressure $>180$ or $<90 \mathrm{~mm} \mathrm{Hg}$, diastolic blood pressure $<50$ or $>105 \mathrm{~mm} \mathrm{Hg}$, heart rate $<50$ or $>120$ bpm, respiratory rate $<8$ or $>24$ breaths/min; abnormalities likely to affect the volume of distribution, e.g. severe oedema), vital signs or electrocardiogram (signs of acute ischaemia, abnormal heart rhythm and any change in ECG from the last routinely recorded ECG); concomitant use of opioids or contraindication against their use; concomitant use of monoamine oxidase inhibitors, CYP3A4 and/or CYP2D6 inhibitors and/or CYP3A4 inducers within 2 weeks before study start. Participants were genotyped for CYP2D6 function as described previously [29]. A total of 47 patients were screened and 10 patients (three women and seven men) with a mean age of 52 years were included. Screening failures included 12 patients who were not interested in taking part in the study; 23 who met exclusion criteria and one who was not available on the planned study dates. There were two drop-outs during the study: one participant (no. 3) was called up for renal transplantation $10 \mathrm{~h}$ into the first study session and one patient (no. 5) stopped study participation after the first session because she developed urinary retention. The final study sample therefore consisted of eight patients who completed both test days in the cross-over design and nine patients with intradialysis kinetic data. The patient and haemodialysis characteristics are shown in Table 1.

\section{Study procedures}

Patients were admitted to the study centre at 6.30 a.m. and the study drug was administered at 7.00 a.m. On that day, haemodialysis started at 1 p.m., which was $6 \mathrm{~h}$ after administration of oxycodone/naloxone. The duration of dialysis was according to patients' clinical needs and was on average 4 h $(245 \pm 22 \mathrm{~min})$. Dialysis was performed by trained staff on the haemodialysis unit in a standardized fashion using a Fresenius HF80 polysulfone hollow-fibre high-flux haemodialyser (Fresenius Medical Care, Oberdorf, Switzerland). Patients stayed in the study centre for $24 \mathrm{~h}$. An additional blood sample was collected during a visit $48 \mathrm{~h}$ after dosing.

\section{Study drug}

Oxycodone/naloxone PR (Targin ${ }^{\circledR}$, Mundipharma Medical Company, Basel Branch) was administered at a dose of 5/ $2.5 \mathrm{mg}$ to four patients and $10 / 5 \mathrm{mg}$ to five patients. The $10 /$ $5 \mathrm{mg}$ dose contains $10 \mathrm{mg}$ of oxycodone hydrochloride $(9 \mathrm{mg}$ of oxycodone) and $5 \mathrm{mg}$ of naloxone hydrochloride ( $4.5 \mathrm{mg}$ of naloxone). The study was initially designed using oxycodone/naloxone $10 / 5 \mathrm{mg}$ to maximize the likelihood of being able to determine low drug and metabolite concentrations, while minimizing the occurrence of adverse effects. Interim laboratory analyses revealed good sensitivity of the test method at low concentrations and this, coupled with the development of urinary retention and vomiting in another subject, prompted a protocol amendment to continue the study using oxycodone/naloxone PR 5/2.5 mg.

\section{Measures}

Blood, dialysate and urine sampling. Blood was collected into lithium heparin tubes before and $0.5,1,1.5,2,3,4,5,6,7$, $8,9,10,12,18,24$ and $48 \mathrm{~h}$ after oxycodone/naloxone administration. During haemodialysis, both 'arterial' and 'venous' blood (the line entering and exiting the dialysis system, respectively) and dialysate samples were collected at 6, 7, 8, 9 and $10 \mathrm{~h}$ after 


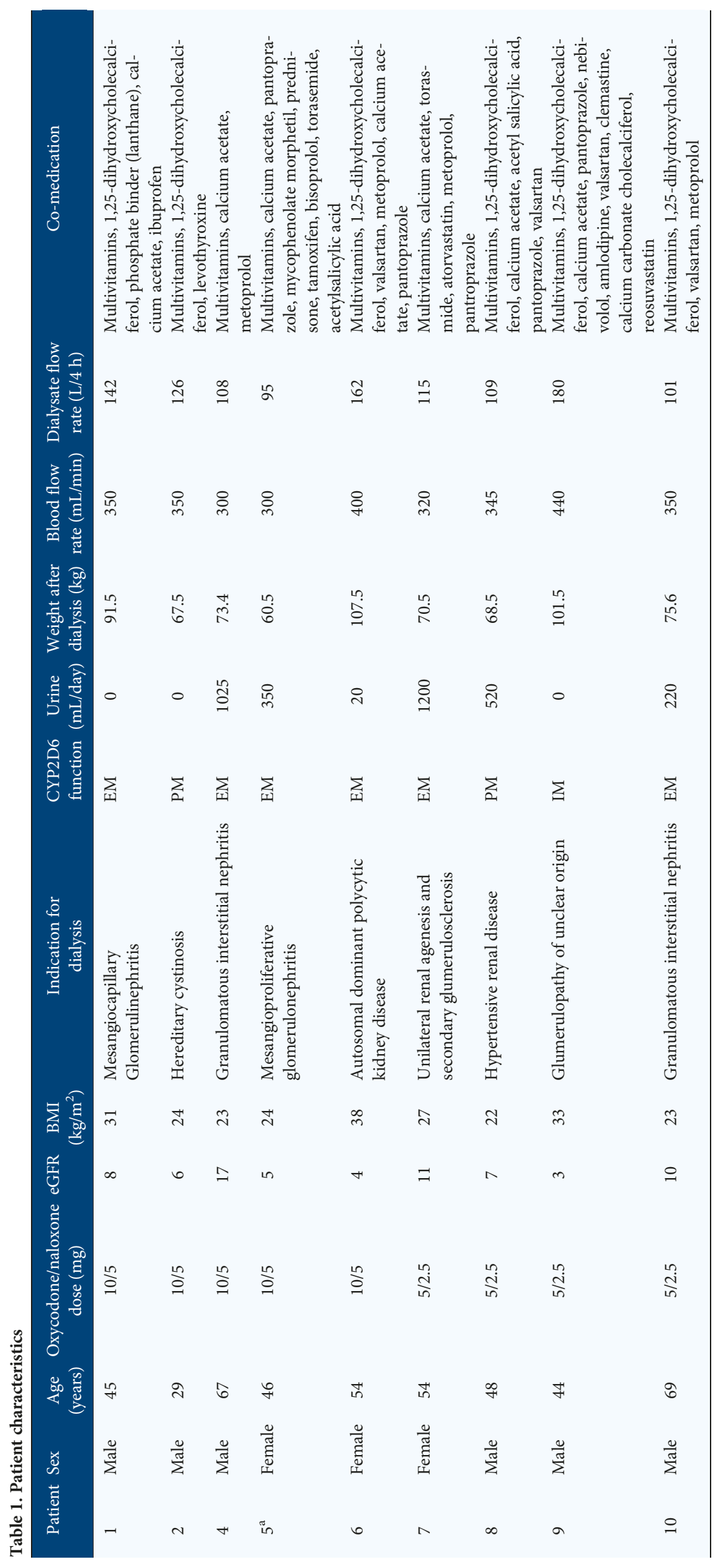


oxycodone/naloxone administration. The plasma and dialysate samples were stored at $-80^{\circ} \mathrm{C}$ until analysis. Total urine was sampled in those subjects who produced urine for $24 \mathrm{~h}$ after dosing.

Analysis of oxycodone, naloxone and metabolite concentrations. Plasma, dialysate and urine concentrations of oxycodone, naloxone, oxymorphone, noroxycodone and noroxymorphone were measured before and after enzymatic deglucuronidation [7] using a high-pressure liquid chromatographytandem mass spectrometry system as described in the Supplementary material online. Concentrations of the glucuronidated (conjugated) analytes were determined indirectly by measuring the analytes after deglucuronidation and subtracting the amount of unconjugated analytes. Results are expressed in units of deconjugated analytes.

\section{Pharmacodynamics}

Subjective effects. Visual analogue scales (VASs) were repeatedly used at the times of blood sampling to assess subjective effects over time. The VASs included separate measures for 'tiredness', 'nausea', 'itching' and 'irritability', and were presented as $100-\mathrm{mm}$ horizontal lines (0-100\%) marked from 'not at all' on the left to 'extremely' on the right.

Pupillary response. Pupillometry was performed before and repeatedly after oxycodone/naloxone administration using a hand-held PRL 200 infrared pupillometer (NeurOptics, Irvine, CA, USA). Pupil function was measured under standardized dark-light conditions and assessed by a Voltcraft MS-1300 luxmeter (Voltcraft, Hirschau, Germany) following a dark adaption time of $1 \mathrm{~min}$ as previously described [30].

\section{Pharmacokinetic analyses}

Blood plasma pharmacokinetics. Non-compartmental analyses were performed using Phoenix WinNonlin 6.4 (Certara, Princeton, NJ, USA). Peak plasma concentration $\left(C_{\max }\right)$ and time to $C_{\max }\left(T_{\max }\right)$ were obtained directly from the observed data. The terminal elimination rate constant $\left(\lambda_{z}\right)$ was estimated by log-linear regression after semi-logarithmic transformation of the data using data points of the terminal linear phase of the concentration-time curve (after the end of haemodialysis on the dialysis day). The terminal half-life $\left(t_{1 / 2}\right)$ was calculated using $\lambda_{\mathrm{z}}$ and the equation $t_{1 / 2}=\ln 2 / \lambda_{\mathrm{z}}$. We also determined the elimination rate constant for oxycodone during the haemodialysis session using the data points obtained at 6,7 , 8,9 and $10 \mathrm{~h}$ after drug administration to calculate the half-life during haemodialysis $\left(t_{1 / 2 \mathrm{~d}}\right)$. The area under the plasma concentration-time curve (AUC) from 0 to $48 \mathrm{~h}$ after dosing $\left(\mathrm{AUC}_{48}\right)$ was calculated using the linear up/log down method. The AUC to infinity $\left(\mathrm{AUC}_{\infty}\right)$ was determined by extrapolation of the $\mathrm{AUC}_{48}$ by using $\lambda_{\mathrm{z}}$. The AUC from 6 to $10 \mathrm{~h}\left(\mathrm{AUC}_{6-10}\right)$ was also calculated to assess the influence of haemodialysis on plasma oxycodone and analyte concentrations during haemodialysis.
Haemodialysis pharmacokinetics. The amount of analyte eliminated by haemodialysis and recovered in the dialysate was calculated as follows: $A_{\mathrm{d}}=C_{\mathrm{d}, 6-10} \times V_{\mathrm{d}}$, with $C_{\mathrm{d}, 6-10}$ being the mean concentration of the analyte in the dialysate and $V_{\mathrm{d}}$ the total dialysate volume (volume/4 h). The clearance by haemodialysis was then calculated using the 'recovery method' as follows: $\mathrm{CL}_{\mathrm{h}, \mathrm{r}}=A_{\mathrm{d}} / \mathrm{AUC}_{\mathrm{art}, 6-10}$ with $\mathrm{AUC}_{\mathrm{art}, 6-10}$ being the AUC in arterial blood plasma taken from the line entering the dialysis system from start to end of the haemodialysis. The haemodialysis clearance $\left(\mathrm{CL}_{\mathrm{h}}, \mathrm{e}\right)$ was also calculated by the 'extraction method' as follows: $\mathrm{CL}_{\mathrm{h}}=Q \times E$ where $Q$ is the haemodialysis blood flow and $E$ is the drug extraction ratio by haemodialysis. $E$ was calculated as follows: $E=\left(C_{\mathrm{a}}-C_{\mathrm{v}}\right) / C_{\mathrm{a}}$, where $C_{\mathrm{a}}$ is the concentration of the analyte in arterial blood plasma entering the dialysis system and $C_{\mathrm{v}}$ is the concentration of the analyte in the blood plasma exiting the dialysis system and entering the venous system of the patient.

\section{Statistical analyses}

The analysis of the pharmacokinetic parameters was descriptive. Geometric means, percentage coefficients of variation (CV\%) and summary statistics for the graphs were calculated within WinNonlin. The pharmacokinetic parameters with and without haemodialysis were then compared within subjects using paired T-tests (Statistica 12 software; StatSoft, Tulsa, OK, USA). Parameters are shown for each dose separately $(n=4$ and 5 for $5 / 2.5$ and $10 / 5 \mathrm{mg}$ of oxycodone/naloxone, respectively). For the main analyte oxycodone, data standardized to the $10 / 5 \mathrm{mg}$ dose are also shown for the whole group. For this standardization, drug concentrations measured in subjects who received the $5 / 2.5 \mathrm{mg}$ dose were multiplied by 2 for each time point prior to the pharmacokinetic analyses. This standardization method assumes a linear dose-concentration relationship for oxycodone. Statistical comparisons were only performed on data for both doses combined and on the subjects who completed both study conditions $(n=8)$.

\section{RESULTS}

\section{Blood plasma pharmacokinetics}

The blood plasma pharmacokinetic parameters for oxycodone for each dose and the entire study group are shown in Table 2. Parameters for the oxycodone metabolites, naloxone and its metabolite naloxone-3-glucuronide are shown in Table 3. The plasma concentration-time curves for oxycodone and its metabolites are shown in Figures 1 and 2. Curves for naloxone and naloxone-3-glucuronide are shown in Figure 3.

In patients with ESRD, haemodialysis reduced the plasma concentrations of unconjugated oxycodone as evidenced by a significant reduction in $\mathrm{AUC}_{6-10}$ by $21 \%\left(T_{1,7}=6.94\right.$, $\mathrm{P}<0.001)$ in the haemodialysis versus non-haemodialysis condition (Table 2), indicating a $26 \%$ increase in total clearance (CL) during haemodialysis $\left(\mathrm{CL}_{\mathrm{h}}+\mathrm{CL}_{\text {intrinsic }}\right)$ compared with no haemodialysis $\left(\mathrm{CL}_{\text {intrinsic }}\right)$. The $\mathrm{AUC}_{48}$ and $\mathrm{AUC}_{\infty}$ were also significantly lower after haemodialysis compared with no haemodialysis $\left(-16 \%, T_{1,7}=2.62, \mathrm{P}=0.03\right.$ and $-14 \%, T_{1,7}=3.66$, $\mathrm{P}=0.008$; respectively) (Table 2 ). The apparent time-averaged 
oxycodone/naloxone $5 / 2.5 \mathrm{mg}$
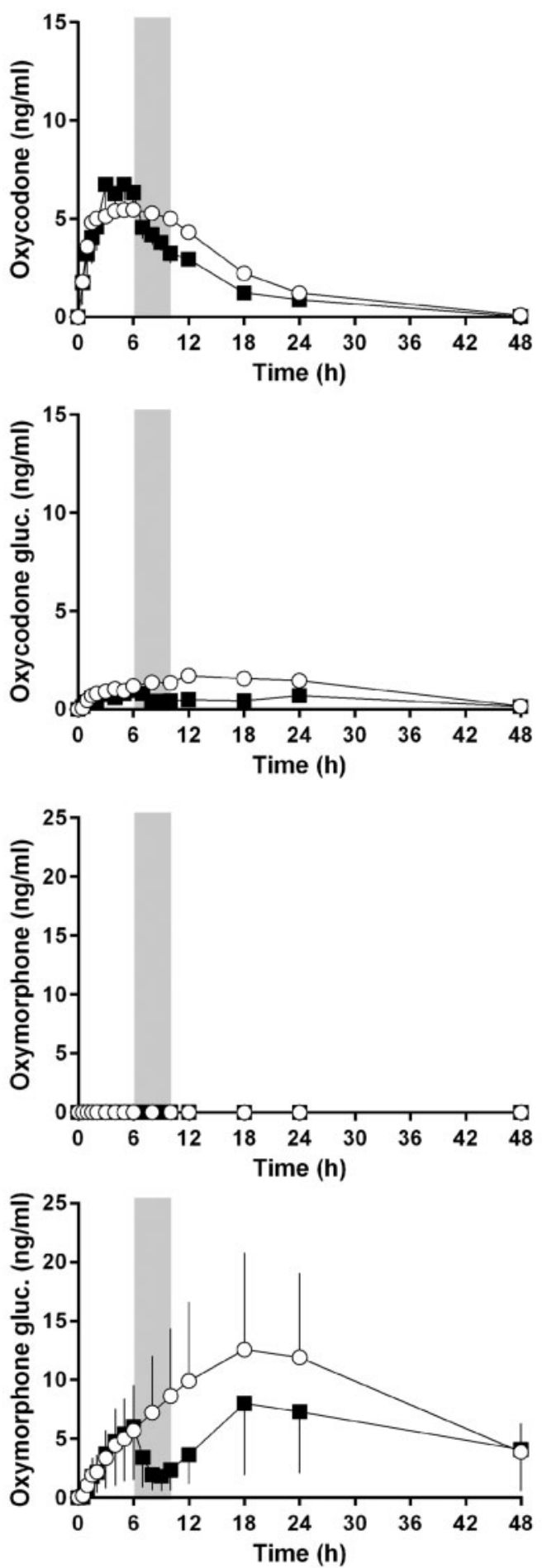

oxycodone/naloxone $10 / 5 \mathrm{mg}$
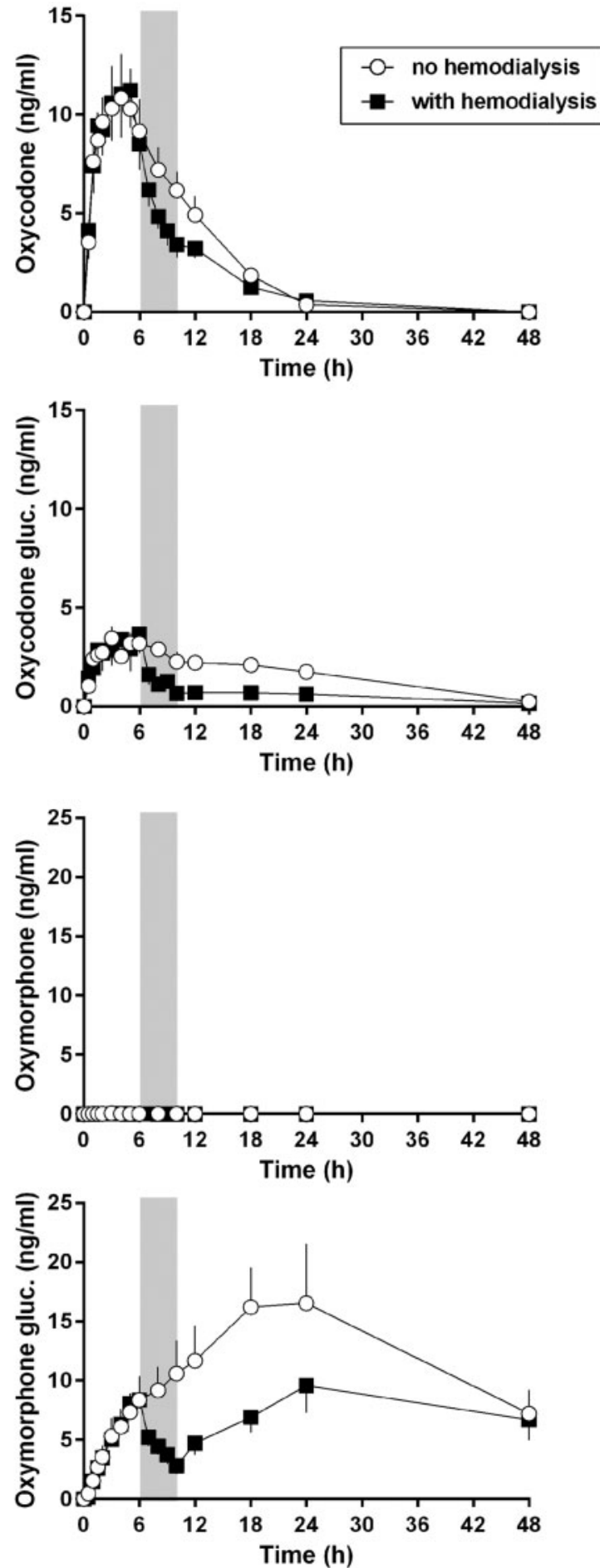

FIGURE 1: Plasma concentration-time curves of oxycodone and its metabolite oxymorphone shown as unconjugated (free) and glucuronide concentrations in patients with ESRD with and without haemodialysis. Oxycodone/naloxone was administered at time $=0$ at a dose of $5 /$ $2.5 \mathrm{mg}$ in four patients (left-hand panel) and at a dose of $10 / 5 \mathrm{mg}$ in another four patients (right-hand panel). Haemodialysis took place 6-10 h after drug administration (grey area). Data are mean and SEM. Concentrations of the glucuronidated analytes were determined indirectly by measuring the analytes after deglucuronidation and subtracting the amount of unconjugated analytes. Concentrations are those of the unconjugated analytes without glucuronate.

total clearance from plasma $\left(\mathrm{CL}_{\text {tot }} / F\right)$ was significantly increased $(+22 \%)$ after haemodialysis compared with no haemodialysis $\left(T_{1,7}=3.26, \mathrm{P}=0.014\right)$ (Table 2). Plasma concentrations of oxycodone declined much faster during the 4-h haemodialysis period compared with after haemodialysis or the no haemodialysis day (Figure 1). The elimination half-life assessed during haemodialysis $6-10 \mathrm{~h}$ after dosing $\left(t_{1 / 2} \mathrm{~d}\right)$ was significantly shorter than the terminal elimination half-life $\left(t_{1 / 2}\right)$ after the haemodialysis 
oxycodone/naloxone $5 / 2.5 \mathrm{mg}$
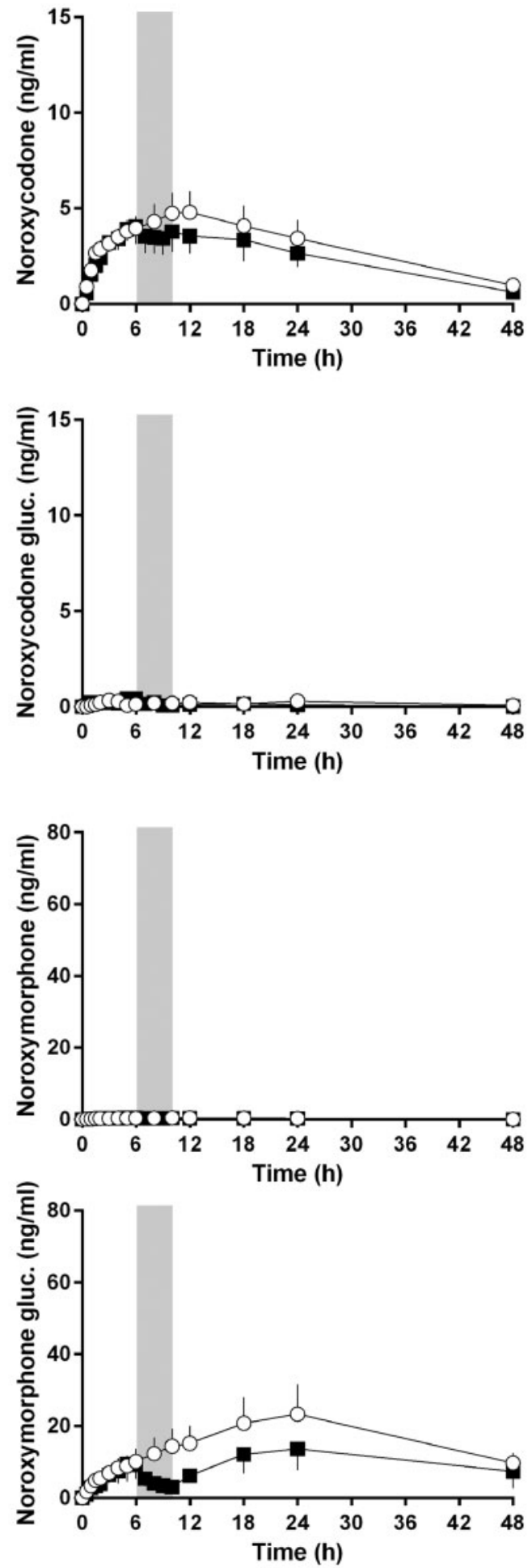

oxycodone/naloxone $10 / 5 \mathrm{mg}$
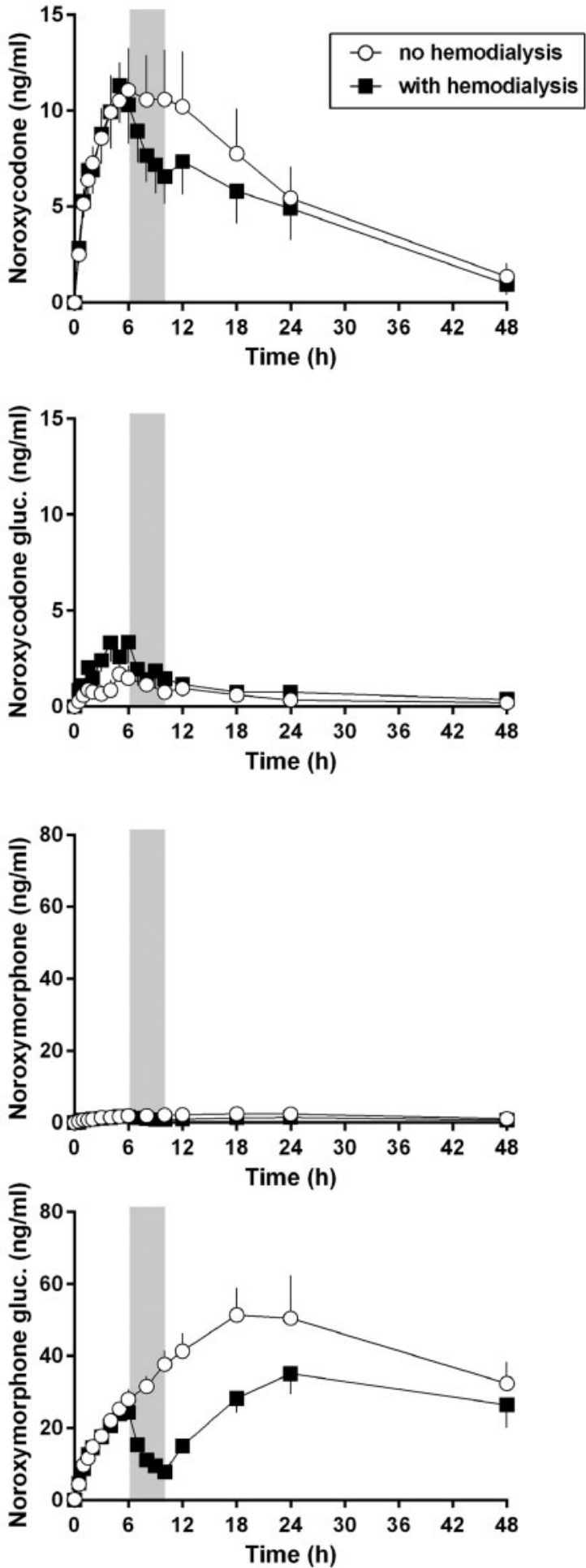

FIGURE 2: Plasma concentration-time curves of oxycodone metabolites noroxycodone and noroxymorphone shown as unconjugated (free) and glucuronide concentrations in patients with ESRD with and without haemodialysis. Oxycodone/naloxone was administered at time $=0$ at a dose of 5/2.5 mg in four patients (left-hand panel) and at a dose of 10/5 mg in another four patients (right-hand panel). Haemodialysis took place 6-10 h after drug administration (grey area). Data are mean and SEM. Concentrations of the glucuronidated analytes were determined indirectly by measuring the analytes after deglucuronidation and subtracting the amount of unconjugated analytes. Concentrations are those of the unconjugated analytes without glucuronate. 


\section{oxycodone/naloxone $5 / 2.5 \mathrm{mg}$}
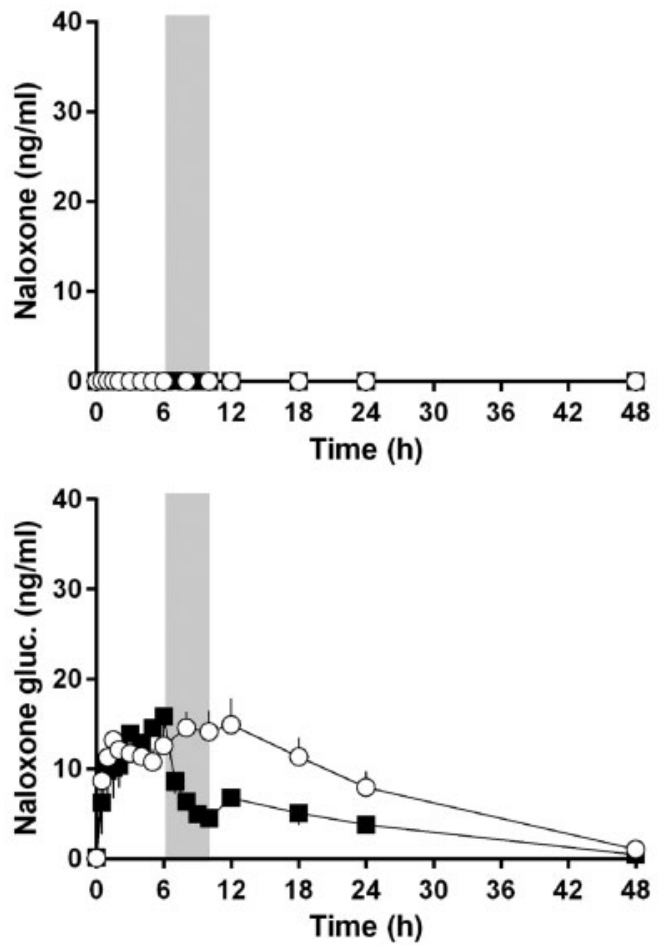

\section{oxycodone/naloxone $10 / 5 \mathrm{mg}$}
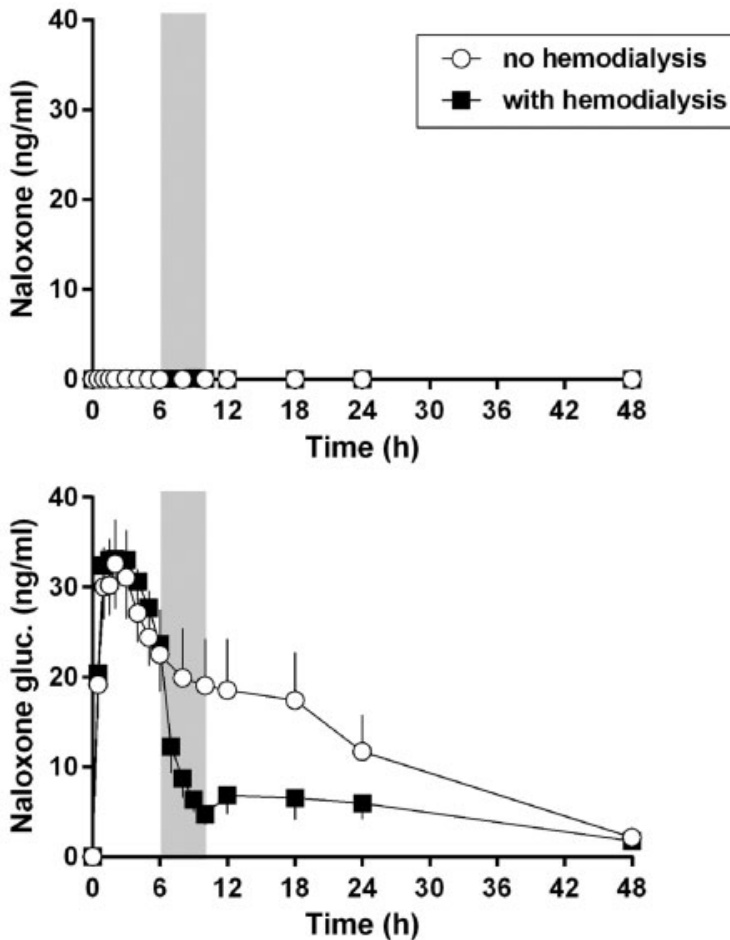

FIGURE 3: Plasma concentration-time curves of naloxone and naloxone glucuronide in patients with ESRD with and without haemodialysis. No active, non-glucuronidated naloxone was detected in plasma. Oxycodone/naloxone was administered at time $=0$ at a dose of $5 / 2.5 \mathrm{mg}$ in four patients (left-hand panel) and at a dose of $10 / 5 \mathrm{mg}$ in another four patients (right-hand panel). Haemodialysis took place 6-10 h after drug administration (grey area). Data are mean and SEM. Concentrations of the naloxone-3-glucuronide were determined indirectly by measuring naloxone after deglucuronidation and subtracting the amount of unconjugated naloxone. Concentrations are those of the unconjugated analytes without glucuronate.

Table 2. Pharmacokinetics of oxycodone with and without haemodialysis

\begin{tabular}{|c|c|c|c|c|c|c|c|c|c|c|c|}
\hline$n$ & Dose & & $\begin{array}{c}C_{\max } \\
(\mathrm{ng} / \mathrm{mL})\end{array}$ & $\begin{array}{l}t_{\max } \\
(\mathrm{h})^{\mathrm{a}}\end{array}$ & $\begin{array}{c}\mathrm{CL}_{\text {tot }} / F \\
(\mathrm{~L} / \mathrm{h})\end{array}$ & $t_{1 / 2}(\mathrm{~h})$ & $t_{1 / 2 \mathrm{~d}}(\mathrm{~h})$ & $V_{\mathrm{d}} / F(\mathrm{~L})$ & $\begin{array}{l}\mathrm{AUC}_{6-10} \\
(\mathrm{ng} \cdot \mathrm{h} / \mathrm{mL})\end{array}$ & $\begin{array}{c}\mathrm{AUC}_{48} \\
\text { (ng.h/mL) }\end{array}$ & $\begin{array}{c}\mathrm{AUC}_{\infty} \\
\text { (ng.h/mL) }\end{array}$ \\
\hline \multicolumn{12}{|c|}{ Without dialysis } \\
\hline \multirow[t]{2}{*}{4} & $5 \mathrm{mg}$ & Geometric mean (CV\%) & $5.8(11)$ & 4.5 & $46(23)$ & $6.4(22)$ & & $428(10)$ & $21(14)$ & $95(25)$ & $97(23)$ \\
\hline & & Range & $5.2-6.5$ & $1.5-6$ & $37-63$ & $4.7-7.5$ & & $400-493$ & $18-24$ & $68-120$ & $72-122$ \\
\hline \multirow[t]{2}{*}{4} & $10 \mathrm{mg}$ & Geometric mean (CV\%) & $11(40)$ & 3.5 & $75(36)$ & $4.9(14)$ & & $532(39)$ & $28(33)$ & $111(35)$ & $120(36)$ \\
\hline & & Range & $6.7-16$ & $2-4$ & $54-112$ & $4.4-6$ & & $360-761$ & $21-29$ & $77-154$ & $80-168$ \\
\hline \multirow[t]{2}{*}{8} & Both doses ${ }^{c}$ & Geometric mean (CV\%) & $11(27)$ & 4 & $59(38)$ & $5.7(22)$ & $5.7(22)$ & $480(28)$ & $34(32)$ & $145(41)$ & $153(38)$ \\
\hline & & Range & $6.7-16$ & $1.5-6$ & $37-112$ & $4.4-7.5$ & $4.4-7.5$ & $360-761$ & $21-48$ & $77-240$ & $80-243$ \\
\hline \multicolumn{12}{|c|}{ With dialysis } \\
\hline \multirow[t]{2}{*}{4} & $5 \mathrm{mg}$ & Geometric mean (CV\%) & $7.5(33)$ & 4 & $56(33)$ & $6.5(40)$ & $4.6(30)$ & $522(12)$ & $17(25)$ & $74(30)$ & $81(33)$ \\
\hline & & Range & $5.1-10$ & $2-6$ & $43-84$ & $3.9-9.6$ & $3.6-7.1$ & $471-595$ & $14-23$ & $52-103$ & $53-105$ \\
\hline \multirow[t]{2}{*}{5} & $10 \mathrm{mg}$ & Geometric mean (CV\%) & $11(32)$ & 4 & $9735)$ & $4.4(22)$ & $2.9(20)$ & $608(21)$ & $20(28)$ & $90(34)$ & $93(35)$ \\
\hline & & Range & $7.4-17$ & $1.5-5$ & $62-139$ & $3.1-5.4$ & $2.4-3.9$ & $480-791$ & $14-28$ & $63-140$ & $65-146$ \\
\hline \multirow[t]{2}{*}{$8^{\mathrm{b}}$} & Both doses ${ }^{c}$ & Geometric mean (CV\%) & $13(36)$ & 3.5 & $72(42)^{*}$ & $5.5(32)$ & $3.9(39)^{\star \star \star}, \dagger$ & $573(20)$ & $27(39)^{\star * \star}$ & $122(40)^{\star}$ & $131(44)^{\star *}$ \\
\hline & & Range & $7.4-20$ & $1.5-6$ & $43-139$ & $3.9-9.6$ & $2.4-7.1$ & $472-792$ & $14-46$ & $63-206$ & 65-208 \\
\hline
\end{tabular}

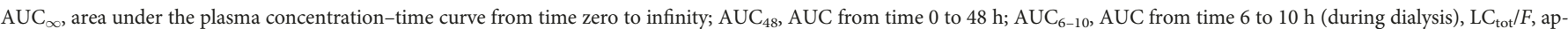
parent total clearance from plasma after oral administration; $C_{\max }$, maximum plasma concentration; $t_{1 / 2}$, terminal plasma elimination half-life; $t_{1 / 2} \mathrm{~d}$, plasma elimination half-life during dialysis $(6-10 \mathrm{~h}) ; t_{\max }$, time to reach $C_{\max } ; V_{\mathrm{D}} / F$, apparent volume of distribution after oral administration.

${ }^{\mathrm{a}}$ Median; ${ }^{\mathrm{b}}$ only those eight subjects with matching non-dialysis data (excluding one subject without non-dialysis data); ${ }^{\mathrm{c}}$ normalized to $10 \mathrm{mg}$.

${ }^{*} \mathrm{P}<0.05$,

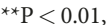

$* * * \mathrm{P}<0.001$, significant difference compared with the non-dialysis condition.

${ }^{+} \mathrm{P}<0.05$ significant difference compared with $t_{1 / 2}$ after dialysis. Statististical tests were only performed on the groups including both doses $(n=8)$. 
Table 3. Pharmacokinetics of oxycodone metabolites with and without haemodialysis

\begin{tabular}{|c|c|c|c|c|c|c|c|c|c|}
\hline Analyte & Haemodialysis & $n$ & $\begin{array}{l}\text { Dose } \\
(\mathrm{mg})\end{array}$ & $\begin{array}{c}C_{\max } \\
(\mathrm{ng} / \mathrm{mL})\end{array}$ & $t_{\max }(\mathbf{h})^{\mathrm{a}}$ & $\begin{array}{l}\mathrm{AUC}_{6-10} \\
(\mathrm{ng} \cdot \mathrm{h} / \mathrm{mL})\end{array}$ & $\begin{array}{c}\mathrm{AUC}_{48} \\
(\mathrm{ng} \cdot \mathrm{h} / \mathrm{mL})\end{array}$ & $\begin{array}{c}\mathrm{AUC}_{\infty} \\
(\mathrm{ng} \cdot \mathrm{h} / \mathrm{mL})\end{array}$ & $t_{1 / 2}(\mathrm{~h})$ \\
\hline \multirow[t]{4}{*}{ Oxycodone glucuronide } & No & 4 & 5 & $1.8(34)$ & 12 & $5.2(23)$ & $39(52)$ & $66(29)$ & NA \\
\hline & No & 4 & 10 & $3.4(31)$ & 3 & $11(33)$ & $70(40)$ & $81(22)$ & NA \\
\hline & Yes & 4 & 5 & $1.1(28)$ & 4.5 & $2.0(50)$ & $19(38)$ & $29(29)$ & NA \\
\hline & Yes & 5 & 10 & $3.6(53)$ & 5 & $5.5(56)$ & $35(71)$ & $49(57)$ & NA \\
\hline \multirow[t]{4}{*}{ Oxymorphone } & No & 4 & 5 & $<\mathrm{LLOQ}$ & NA & 0 & 0 & 0 & NA \\
\hline & No & 4 & 10 & $<\mathrm{LLOQ}$ & NA & 0 & 0 & 0 & NA \\
\hline & Yes & 4 & 5 & $<$ LLOQ & NA & 0 & 0 & 0 & NA \\
\hline & Yes & 5 & 10 & $<$ LLOQ & NA & 0 & 0 & 0 & NA \\
\hline \multirow[t]{4}{*}{ Oxymorphone glucuronides } & No & 4 & 5 & ${ }^{b} 13 \pm 16$ & 21 & ${ }^{b} 29 \pm 38$ & $\mathrm{~b}_{394 \pm 500}$ & b $790 \pm 411$ & $19(51)$ \\
\hline & No & 4 & 10 & ${ }^{b} 18 \pm 9$ & 24 & $\mathrm{~b}_{37} \pm 18$ & $\mathrm{~b}_{556} \pm 302$ & $\mathrm{~b}_{394} \pm 500$ & $21(39)$ \\
\hline & Yes & 4 & 5 & $b_{7.2} \pm 10$ & 24 & ${ }^{b} 15 \pm 17$ & $\mathrm{~b}_{246} \pm 370$ & NA & NA \\
\hline & Yes & 5 & 10 & ${ }^{b} 12 \pm 4.8$ & 24 & ${ }^{b_{2}} 20 \pm 5.7$ & $\mathrm{~b}_{398} \pm 172$ & NA & NA \\
\hline \multirow[t]{4}{*}{ Noroxycodone } & No & 4 & 5 & $4.6(49)$ & 11 & $16(45)$ & $128(63)$ & $145(71)$ & $14(26)$ \\
\hline & No & 4 & 10 & $11(41)$ & 6 & $40(49)$ & $231(76)$ & $275(67)$ & $13(23)$ \\
\hline & Yes & 4 & 5 & $4.1(38)$ & 5.5 & $13(54)$ & $95(76)$ & $111(67)$ & $13(15)$ \\
\hline & Yes & 5 & 10 & $10(34)$ & 5 & $27(43)$ & $155(82)$ & $187(75)$ & $12(33)$ \\
\hline \multirow[t]{4}{*}{ Noroxycodone glucuronides } & No & 4 & 5 & ${ }^{b} 0.6 \pm 0.5$ & 3 & ${ }^{b} 0.7 \pm 1.2$ & ${ }^{b} 8.6 \pm 15$ & NA & NA \\
\hline & No & 4 & 10 & $\mathrm{~b}_{2.1} \pm 1.6$ & 5 & b $4.5 \pm 4.0$ & $\mathrm{~b}_{23} \pm 16$ & NA & NA \\
\hline & Yes & 4 & 5 & ${ }^{\mathrm{b}} 0.5 \pm 0.4$ & 5 & ${ }^{b} 0.9 \pm 0.6$ & $\mathrm{~b}_{4.6} \pm 5.8$ & NA & NA \\
\hline & Yes & 5 & 10 & $\mathrm{~b}_{3.6 \pm 2.0}$ & 4 & ${ }^{b} 6.9 \pm 6.0$ & $\mathrm{~b}_{41} \pm 36$ & NA & NA \\
\hline \multirow[t]{4}{*}{ Noroxymorphone } & No & 4 & 5 & ${ }^{\mathrm{b}} 0.4 \pm 0.6$ & 11 & ${ }^{b} 1.5 \pm 0.6$ & ${ }^{b} 11 \pm 17$ & NA & NA \\
\hline & No & 4 & 10 & $\mathrm{~b}_{2.6} \pm 0.8$ & 21 & b $8.0 \pm 2.4$ & ${ }^{\mathrm{b}} 91 \pm 31$ & ${ }^{b} 129 \pm 30$ & $24(30)$ \\
\hline & Yes & 4 & 5 & ${ }^{b} 0.4 \pm 0.7$ & 5.5 & ${ }^{b} 1.3 \pm 1.6$ & b $6.3 \pm 7.7$ & NA & NA \\
\hline & Yes & 5 & 10 & $\mathrm{~b}_{2.1} \pm 0.6$ & 6 & $\mathrm{~b}_{5} .0 \pm 2.3$ & ${ }^{\mathrm{b}} 62 \pm 20$ & ${ }^{b} 125 \pm 78$ & $35(64)$ \\
\hline \multirow[t]{4}{*}{ Noroxymorphone glucuronides } & No & 4 & 5 & $20(65)$ & 24 & $42(64)$ & $664(61)$ & NA & NA \\
\hline & No & 4 & 10 & $55(33)$ & 24 & $127(21)$ & $1857(34)$ & NA & NA \\
\hline & Yes & 4 & 5 & $11(83)$ & 24 & $15(74)$ & 335 (93) & NA & NA \\
\hline & Yes & 5 & 10 & $42(36)$ & 24 & $51(16)$ & $1388(35)$ & NA & NA \\
\hline \multirow[t]{4}{*}{ Naloxone } & No & 4 & 5 & $<$ LLOQ & NA & 0 & 0 & 0 & NA \\
\hline & No & 4 & 10 & $<\mathrm{LLOQ}$ & NA & 0 & 0 & 0 & NA \\
\hline & Yes & 4 & 5 & $<$ LLOQ & NA & 0 & 0 & 0 & NA \\
\hline & Yes & 5 & 10 & $<$ LLOQ & NA & 0 & 0 & 0 & NA \\
\hline \multirow[t]{4}{*}{ Naloxone glucuronide } & No & 4 & 5 & $15(30)$ & 6.5 & $54(30)$ & $358(38)$ & $371(38)$ & $9.2(11)$ \\
\hline & No & 4 & 10 & 33 (39) & 2 & $73(61)$ & 549 (61) & 586 (59) & $12(21)$ \\
\hline & Yes & 4 & 5 & $17(20)$ & 5 & $27(34)$ & $200(26)$ & $216(26)$ & NA \\
\hline & Yes & 5 & 10 & $37(43)$ & 3 & 37 (57) & $351(75)$ & $425(60)$ & NA \\
\hline
\end{tabular}

Values are geometric means (CV\%). Concentrations of the unconjugated analytes were determined in blood plasma without deglucuronidation. Concentrations of the glucuronidated analytes were determined indirectly by measuring the analytes after deglucuronidation and subtracting the amount of unconjugated analytes. Concentrations are those of the unconjugated analytes without glucuronate.

${ }^{a}$ Median values are shown for $t_{\max }$.

${ }^{b}$ Values are arithmetric means \pm SDs if geometric mean could not be calculated due to some values $=0$.

$\mathrm{AUC}_{\infty}$, area under the plasma concentration-time curve from time zero to infinity; $\mathrm{AUC}_{48}, \mathrm{AUC}$ from time 0 to $48 \mathrm{~h} ; \mathrm{AUC}$ 6-10, $\mathrm{AUC}$ from time 6 to $10 \mathrm{~h}$ (during dialysis), $\mathrm{LC}$ tot $/ F$, apparent total clearance from plasma after oral administration; $C_{\max }$, maximum plasma concentration; LLOQ, lower limit of quantification; $t_{\text {max }}$, time to reach $C_{\text {max }} ; t_{1 / 2}$, terminal plasma elimination half-life.

$\left(T_{1,7}=2.96, \mathrm{P}=0.02\right)$ or compared with that on the day without haemodialysis $\left(T_{1,7}=4.09, \mathrm{P}=0.005\right)$ while terminal $t_{1 / 2}$ values did not differ between the haemodialysis and no haemodialysis conditions $\left(T_{1,7}=0.06, \mathrm{P}=0.95\right)$ (Table 2). $C_{\max }, T_{\max }$ and apparent volume of distribution $\left(V_{\mathrm{D}} / F\right)$ values did not differ significantly between the haemodialysis and no haemodialysis conditions $\left(T_{1,7}=2.01, \mathrm{P}=0.08 ; T_{1,7}=0.0, \mathrm{P}=1.0\right.$; and $T_{1,7}=$ $2.29, \mathrm{P}=0.06$; respectively) (Table 2 ).

Oxycodone was present in plasma mostly in its free unconjugated form (Figure 1). Similarly, noroxycodone circulated mainly in its free form (Figure 2) while oxymorphone (Figure 1) and noroxymorphone (Figure 2) were present almost exclusively as glucuronides. Free plasma concentrations of the active and potent metabolite oxymorphone were therefore very low (Figure 1). Orally administered naloxone is intended to act only in the gut, and in this study, we also found that it circulated exclusively in its inactive glucuronide form while free naloxone could not be detected in plasma (Figure 3).

\section{Intradialysis kinetics}

The haemodialysis pharmacokinetic parameters for all analytes are shown in Table 4. The haemodialysis blood flow was kept stable in all patients during dialysis and ranged from 18 to $26 \mathrm{~L} / \mathrm{h}$ (mean $\pm \mathrm{SD}=21.4 \pm 2.5$ ). The extraction ratio for oxycodone was $0.47 \pm 0.10$. The oxycodone clearance by haemodialysis $\left(\mathrm{CL}_{\mathrm{h}}, \mathrm{r}\right)$ calculated using the recovery of oxycodone in the dialysate was $8.4 \pm 2.1 \mathrm{~L} / \mathrm{h}$ and the clearance calculated using the haemodialysis blood flow and extraction rate $\left(\mathrm{CL}_{\mathrm{h}, \mathrm{e}}\right)$ was $9.8 \pm 1.7 \mathrm{~L} / \mathrm{h}$. The $\mathrm{CL}_{\mathrm{h}, \mathrm{r}}$ values were smaller than $\mathrm{CL}_{\mathrm{h}, \mathrm{e}}$ values for all analytes, possibly due to adsorption of analytes to the filter and tubing (Table 4). In total, $2.5 \%$ of the administered dose of oxycodone was recovered as unconjugated oxycodone 
Table 4. Intradialysis kinetics of oxycodone, naloxone and metabolites

\begin{tabular}{lccccccc} 
& $\begin{array}{c}\mathrm{AUC}_{\mathrm{art}, 6-10 \mathrm{~h}} \\
(\mathrm{ng} / \mathrm{mL} \cdot \mathrm{h})\end{array}$ & $\begin{array}{c}\text { Extraction ratio } \\
(E)\end{array}$ & $\begin{array}{c}\mathrm{CL}_{\mathrm{h}, \mathrm{e}} \\
(\mathrm{L} / \mathrm{h})\end{array}$ & $\begin{array}{c}\mathrm{CL}_{\mathrm{h}, \mathrm{r}} \\
(\mathrm{L} / \mathrm{h})\end{array}$ & $\begin{array}{c}\mathrm{A}_{\mathrm{d}} \\
(\mu \mathrm{mol} / 4 \mathrm{~h})\end{array}$ & $\begin{array}{c}\% \text { of dose } \\
(\% \mathrm{~mol} . \text { weight })\end{array}$ \\
$\begin{array}{lccccc}\mathrm{A}_{\mathrm{u}} \\
(\mu \mathrm{mol} / 24 \mathrm{~h})\end{array}$ \\
Oxycodone & $19 \pm 4.8$ & $0.47 \pm 0.1$ & $9.8 \pm 1.7$ & $8.4 \pm 2.1$ & $0.50 \pm 0.15$ & $2.5 \pm 1.1$ & $0.03 \pm 0.02$ \\
Oxycodone glucuronide & $4.3 \pm 2.7$ & $0.54 \pm 0.1$ & $11 \pm 1.6$ & $6.5 \pm 3.6$ & $0.06 \pm 0.02$ & $0.3 \pm 0.2$ & $0.002 \pm 0.004$ \\
Naloxone & 0 & $\mathrm{NA}$ & $\mathrm{NA}$ & $\mathrm{NA}$ & $<0.01$ & $0.03 \pm 0.04$ & $<0.001$ \\
Naloxone glucuronide & $35 \pm 13$ & $0.71 \pm 0.1$ & $15 \pm 0.7$ & $6.6 \pm 3.5$ & $0.65 \pm 0.28$ & $6.7 \pm 3.9$ & $0.09 \pm 0.08$ \\
Oxymorphone & 0 & $\mathrm{NA}$ & $\mathrm{NA}$ & $\mathrm{NA}$ & $<0.01$ & $0.01 \pm 0.03$ & $<0.001$ \\
Oxymorphone glucuronides & $16 \pm 11$ & $0.78 \pm 0.05$ & $16 \pm 1.2$ & $5.2 \pm 2.5$ & $0.23 \pm 0.16$ & $1.0 \pm 0.9$ & $0.06 \pm 0.09$ \\
Noroxycodone & $23 \pm 12$ & $0.40 \pm 0.10$ & $8.2 \pm 1.5$ & $8.1 \pm 2.2$ & $0.58 \pm 0.27$ & $2.6 \pm 0.7$ & $0.09 \pm 0.1$ \\
Noroxycodone glucuronides & $4.2 \pm 5.1$ & $0.37 \pm 0.33$ & $7.3 \pm 6.3$ & $5.0 \pm 7.0$ & $0.05 \pm 0.07$ & $0.2 \pm 0.2$ & $0.08 \pm 0.1$ \\
Noroxymorphone & $3.4 \pm 2.6$ & $0.54 \pm 0.07$ & $11 \pm 2.0$ & $5.3 \pm 2.6$ & $0.05 \pm 0.06$ & $0.2 \pm 0.3$ & $0.007 \pm 0.007$ \\
Noroxymorphone glucuronides & $37 \pm 19$ & $0.78 \pm 0.08$ & $16 \pm 0.9$ & $7.3 \pm 2.5$ & $0.85 \pm 0.47$ & $3.8 \pm 2.0$ & $0.09 \pm 0.1$ \\
\hline
\end{tabular}

Values are mean \pm SD in nine patients. Concentrations of the glucuronidated analytes were determined indirectly by measuring the analytes after deglucuronidation and subtracting the amount of unconjugated analytes. Concentrations are those of the unconjugated analytes without glucuronate.

$\mathrm{AUC}_{\mathrm{art}, 6-10 \mathrm{~h}}$, area under the plasma concentration-time curve from 6 to $10 \mathrm{~h}$ after dosing during haemodialysis (arterial = line entering the dialyser); $E$, drug extraction ratio by haemodialysis; $\mathrm{CL}_{\mathrm{h}, \mathrm{e}}$, clearance by haemodialysis calculated by the extraction method, $\mathrm{CL}_{\mathrm{h}, \mathrm{r}}$, clearance by haemodialysis calculated by the recovery method; $\mathrm{A}_{\mathrm{d}}$, amount of analyte recovered in the dialysate; $A_{u}$, amount of analyte recovered in urine; NA, not assessed.

in the dialysate and only $0.3 \%$ as oxycodone glucuronide. Oxymorphone, noroxymorphone and naloxone were almost exclusively eliminated as glucuronides (1.0, 3.8 and $6.7 \%$ of the dose, respectively) while noroxycodone was mainly eliminated as unconjugated metabolite (2.6\% of the dose, Table 4$)$. Only $\sim 2 \%$ of the oxycodone dose was recovered as oxycodone or its metabolites in urine (Table 4).

\section{Pharmacodynamics and safety}

Oxycodone/naloxone induced only small changes in subjective ratings for tiredness, itching, nausea and irritability, with no relevant differences between study day with or without haemodialysis (Supplementary data, Figure S1). Oxycodone/naloxone had no effects on pupil function in this study population. There was a decrease in pupil size during haemodialysis compared with no haemodialysis after the $5 / 2.5 \mathrm{mg}$ but not after the $10 / 5 \mathrm{mg}$ oxycodone/naloxone dose. One female patient developed urinary retention $5-25 \mathrm{~h}$ after dosing on the dialysis day and consequently stopped participation in the study. Another patient vomited 1.5, 2.5 and $9 \mathrm{~h}$ after dosing and was treated with an antiemetic. Other attributable adverse drug effects were (out of a total of 18 drug exposure episodes): nausea (6/18), tiredness (2/18), headache (2/18) and 1/18 each of relaxed feeling, hiccups, constipation, dizziness, dry mouth and cough.

\section{DISCUSSION}

The present study describes for the first time the plasma, dialysate and urine pharmacokinetics of oxycodone/naloxone and metabolites in patients with ESRD undergoing intermittent haemodialysis.

Haemodialysis increased the clearance of oxycodone and all its metabolites. The average plasma extraction ratio for oxycodone was $47 \%$. According to the recovery of oxycodone or its metabolites in the dialysate, $10.6 \%$ of the administered dose of oxycodone was eliminated during $4 \mathrm{~h}$ of haemodialysis performed 6-10 h after dosing (Table 4). Oxycodone and its metabolite noroxycodone were eliminated during dialysis mainly in their unconjugated form. The metabolites oxymorphone and noroxymorphone as well as naloxone were eliminated almost exclusively as conjugates. In subjects with normal renal function, studies have found that on average $7.8 \%$ of an oral or $11-$ $14 \%$ of a parenteral dose of oxycodone were excreted in urine as unconjugated and conjugated oxycodone over $24 \mathrm{~h}[5,19]$. In the present patients, $2.8 \%$ of the oral oxycodone dose was eliminated in the dialysate within only $4 \mathrm{~h}$, indicating that oxycodone is quite effectively cleared from plasma by haemodialysis. Consistent with this observation, the measured plasma half-life for oxycodone was $3.9 \mathrm{~h}$ during haemodialysis, which lies within the range of reported terminal elimination half-lives (3$6.7 \mathrm{~h}$ ) in subjects with normal renal function (Supplementary data, Figure S2) [1, 5, 6, 13, 16-19, 23-26, 31, 32]. Nevertheless, the overall exposure $\left(\mathrm{AUC}_{0-48 \mathrm{~h}}\right.$ ) to oxycodone in plasma was only minimally changed by haemodialysis, consistent with its predominantly hepatic elimination. Specifically, haemodialysis reduced the plasma exposure $\left(\mathrm{AUC}_{0-48} \mathrm{~h}\right)$ to oxycodone by only $16 \%$. Additionally, there was evidence of redistribution from tissue into the circulation after the end of the haemodialysis session. In the present ESRD patients, the terminal elimination half-lives $\left(t_{1 / 2}\right)$ of oxycodone and noroxycodone were approximately 6 and $12 \mathrm{~h}$, respectively. This theoretically translates into accumulation factors of 1.3 and 2 for oxycodone and noroxycodone, respectively, were oxycodone/naloxone PR to be administered every $12 \mathrm{~h}$ rather than as a single dose. Consistent with the present data, the average $t_{1 / 2}$ of oxycodone was $7 \mathrm{~h}$ (median $=3.9 \mathrm{~h}$ ) in 10 patients with ESRD undergoing renal transplantation [19]. In patients with ESRD, the average $t_{1 / 2}$ of oxycodone (6h) was only up to $50 \%$ longer than in subjects with normal renal function $[5,6,13,16-19,23-26,31]$. Additionally, in a study in healthy volunteers using the same oxycodone/naloxone $10 / 5 \mathrm{mg}$ PR formulation, $C_{\max }$ and $\mathrm{AUC}_{\infty}$ values were $10.4 \mathrm{ng} / \mathrm{mL}$ and $128 \mathrm{ng} \cdot \mathrm{h} / \mathrm{mL}$ [1] and therefore similar to the values in the present patients with ESRD. Together, the findings indicate only minimal accumulation of oxycodone in patients with ESRD. Larger accumulation might occur for the metabolites with a longer half-life such as noroxycodone. However, this is unlikely to be of clinical relevance considering its low potency as a $\mu$-opioid receptor agonist and its 
lower brain penetration [10]. Nevertheless, a study using repeated doses is needed to further assess the accumulation of oxycodone and its metabolites in patients with ESRD.

It has been suggested that oxymorphone and noroxymorphone may contribute to the analgesic effects of oxycodone [10, $20,33]$. However, the present study showed that concentrations of the active metabolite oxymorphone and noroxymorphone in their unconjugated form were very low. Additionally, the 3-glucuronides of these two metabolites are also likely inactive at the $\mu$-opioid receptor [11]. Therefore, although metabolites of oxycodone may accumulate due to their longer half-lives in patients with ESRD, opioidergic effects are unlikely. This is in contrast to morphine, where the active morphine-6-glucuronide metabolite accumulates [34-36]. Taken together, our findings do not indicate clinically relevant accumulation of oxycodone or its active free metabolites in patients with ESRD with or without haemodialysis. Therefore, oxycodone can be dosed similarly in patients with ESRD and in patients without renal impairment, according to the severity of their pain. The study also indicates that oxycodone is a suitable opioid in patients with ESRD on haemodialysis as similarly proposed for fentanyl, buprenorphine or methadone [37]. Furthermore, due to oxycodone's low protein binding, patients with hypoalbuminaemia are unlikey to develop rebound pain during or after dialysis, as has been shown for buprenorphine [38]. So, in line with a single previously available case report [27], the present data show that oxycodone is removed during haemodialysis, but probably not to an extent necessitating additional dosing.

In subjects with normal renal function, $\sim 40 \%$ of the administered oxycodone can be recovered in urine as oxycodone or its metabolites [9]. In contrast, in the present ESRD patients, the urinary recovery of oxycodone and its metabolites in their unconjugated and conjugated forms was only $\sim 2 \%$ of the administered dose of oxycodone. This is consistent with the previously reported average $1 \%$ urinary recovery of unconjugated oxycodone in ESRD patients undergoing renal transplantation compared with $11 \%$ in patients with normal renal function [19].

Some studies reported reduced effects of oxycodone in CYP2D6 poor metabolizers compared with extensive metabolizers [20,33,39] or in the presence of CYP2D6 inhibitors [33] while others could not confirm these findings [10, 17, 40,41]. Although we determined CYP2D6 genotypes and included both extensive and poor metabolizers, the sample size was too small to determine the role of CYP2D6 in the pharmacokinetics and pharmacodynamics of oxycodone. Additionally, oxycodone did not induce robust changes in pupil size at the low dose used in the present patients with ESRD and therefore does not seem to be a good biomarker for the opioid effect in these patients in contrast to data from previous studies in healthy and younger subjects $[13,23-25,31]$. Therefore, the pharmacodynamic measures obtained in the present study did not allow for pharmacokinetic-pharmacodynamic modelling or other evaluations of the effects of CYP2D6 function or haemodialysis on the subjective or other pharmacodynamic effects of oxycodone.

In the present study adverse effects of oxycodone included nausea, vomiting and urinary retention as also commonly reported in studies in healthy subjects $[9,31]$. There were no differences in tolerability of oxycodone/naloxone on days with or without haemodialysis.

A strength of the present study was the use of a withinsubject design that allowed us to assess the impact of haemodialysis within the same patients and increased study power. Limitations were the small sample size and that the study did not include an age-matched comparator group with normal renal function.

In conclusion, oxycodone is eliminated during haemodialysis, but not to an extent necessitating additional dosing. The pharmacokinetics of oxycodone in patients with ESRD and the absence of unconjugated active metabolites indicate that oxycodone can be used at usual doses.

\section{SUPPLEMENTARY DATA}

Supplementary data are available at ndt online.

\section{ACKNOWLEDGEMENTS}

The authors thank Claudia Bläsi and Elvira Keil for study management.

\section{FUNDING}

This research was supported from a grant from Mundipharma Medical Company, Basel, and the University Hospital Basel.

\section{AUTHORS' CONTRIBUTIONS}

S.Kr., M.H., S.Ka., M.D. and A.L. designed the research. A.L., U.D., M.D., P.A., A.W.J., C.L., S.Ka., H.MzS. and M.H. performed the research. A.L., U.D., F.H., Y.S. and M.E.L. analysed data. A.L. and M.E.L. wrote the article.

\section{CONFLICT OF INTEREST STATEMENT}

None declared.

\section{REFERENCES}

1. Smith K, Hopp M, Mundin G et al. Naloxone as part of a prolonged release oxycodone/naloxone combination reduces oxycodone-induced slowing of gastrointestinal transit in healthy volunteers. Expert Opin Investig Drugs 2011; 20: 427-439

2. Lowenstein O, Leyendecker P, Hopp M et al. Combined prolonged-release oxycodone and naloxone improves bowel function in patients receiving opioids for moderate-to-severe non-malignant chronic pain: a randomised controlled trial. Expert Opin Pharmacother 2009; 10: 531-543

3. Simpson K, Leyendecker P, Hopp M et al. Fixed-ratio combination oxycodone/naloxone compared with oxycodone alone for the relief of opioidinduced constipation in moderate-to-severe noncancer pain. Curr Med Res Opin 2008; 24: 3503-3512

4. Kimmel PL, Fwu CW, Abbott KC et al. Opioid prescription, morbidity, and mortality in United States dialysis patients. J Am Soc Nephrol 2017; 28: $3658-3670$

5. Poyhia R, Seppala T, Olkkola KT et al. The pharmacokinetics and metabolism of oxycodone after intramuscular and oral administration to healthy subjects. Br J Clin Pharmacol 1992; 33: 617-621

6. Leow KP, Smith MT, Williams B et al. Single-dose and steady-state pharmacokinetics and pharmacodynamics of oxycodone in patients with cancer. Clin Pharmacol Ther 1992; 52: 487-495 
7. Fang WB, Lofwall MR, Walsh SL et al. Determination of oxycodone, noroxycodone and oxymorphone by high-performance liquid chromatographyelectrospray ionization-tandem mass spectrometry in human matrices: in vivo and in vitro applications. J Anal Toxicol 2013; 37: 337-344

8. Marsousi N, Daali Y, Rudaz S et al. Prediction of metabolic interactions with oxycodone via CYP2D6 and CYP3A inhibition using a physiologically based pharmacokinetic model. CPT: Pharmacomet Syst Pharmacol 2014; 3: e152

9. Cone EJ, Heltsley R, Black DL et al. Prescription opioids. I. Metabolism and excretion patterns of oxycodone in urine following controlled single dose administration. J Anal Toxicol 2013; 37: 255-264

10. Lalovic B, Kharasch E, Hoffer C et al. Pharmacokinetics and pharmacodynamics of oral oxycodone in healthy human subjects: role of circulating active metabolites. Clin Pharmacol Ther 2006; 79: 461-479

11. Chen ZR, Irvine RJ, Somogyi AA et al. Mu receptor binding of some commonly used opioids and their metabolites. Life Sci 1991; 48: 2165-2171

12. Peckham EM, Traynor JR. Comparison of the antinociceptive response to morphine and morphine-like compounds in male and female SpragueDawley rats. J Pharmacol Exp Ther 2006; 316: 1195-1201

13. Samer CF, Daali Y, Wagner M et al. The effects of CYP2D6 and CYP3A activities on the pharmacokinetics of immediate release oxycodone. $\mathrm{Br} \mathrm{J}$ Pharmacol 2010; 160: 907-918

14. Yee DA, Best BM, Atayee RS et al. Observations on the urine metabolic ratio of oxymorphone to oxycodone in pain patients. J Anal Toxicol 2012; 36: 232-238

15. Romand S, Spaggiari D, Marsousi N et al. Characterization of oxycodone in vitro metabolism by human cytochromes P450 and UDP-glucuronosyltransferases. J Pharm Biomed Anal 2017; 144: 129-137

16. Poyhia R, Olkkola KT, Seppala T et al. The pharmacokinetics of oxycodone after intravenous injection in adults. Br J Clin Pharmacol 1991; 32: 516-518

17. Kummer O, Hammann F, Moser C et al. Effect of the inhibition of CYP3A4 or CYP2D6 on the pharmacokinetics and pharmacodynamics of oxycodone. Eur J Clin Pharmacol 2011; 67: 63-71

18. Leow KP, Smith MT, Watt JA et al. Comparative oxycodone pharmacokinetics in humans after intravenous, oral, and rectal administration. Ther Drug Monit 1992; 14: 479-484

19. Kirvela $\mathrm{M}$, Lindgren $\mathrm{L}$, Seppala $\mathrm{T}$ et al. The pharmacokinetics of oxycodone in uremic patients undergoing renal transplantation. J Clin Anesth 1996; 8: 13-18

20. Stamer UM, Zhang L, Book M et al. CYP2D6 genotype dependent oxycodone metabolism in postoperative patients. PLoS One 2013; 8: e60239

21. Gronlund J, Saari TI, Hagelberg NM et al. Exposure to oral oxycodone is increased by concomitant inhibition of CYP2D6 and 3A4 pathways, but not by inhibition of CYP2D6 alone. Br J Clin Pharmacol 2010; 70: 78-87

22. Saari TI, Gronlund J, Hagelberg NM et al. Effects of itraconazole on the pharmacokinetics and pharmacodynamics of intravenously and orally administered oxycodone. Eur J Clin Pharmacol 2010; 66: 387-397

23. Nieminen TH, Hagelberg NM, Saari TI et al. Oxycodone concentrations are greatly increased by the concomitant use of ritonavir or lopinavir/ritonavir. Eur J Clin Pharmacol 2010; 66: 977-985

24. Nieminen TH, Hagelberg NM, Saari TI et al. Grapefruit juice enhances the exposure to oral oxycodone. Basic Clin Pharmacol Toxicol 2010; 107: 782-788

25. Nieminen TH, Hagelberg NM, Saari TI et al. St John's wort greatly reduces the concentrations of oral oxycodone. Eur J Pain 2010; 14: 854-859
26. Hagelberg NM, Nieminen TH, Saari TI et al. Voriconazole drastically increases exposure to oral oxycodone. Eur J Clin Pharmacol 2009; 65: 263-271

27. Lee MA, Leng ME, Cooper RM. Measurements of plasma oxycodone, noroxycodone and oxymorphone levels in a patient with bilateral nephrectomy who is undergoing haemodialysis. Palliat Med 2005; 19: 259-260

28. Foral PA, Ineck JR, Nystrom KK. Oxycodone accumulation in a hemodialysis patient. South Med J 2007; 100: 212-214

29. Schmid Y, Vizeli P, Hysek CM et al. CYP2D6 function moderates the pharmacokinetics and pharmacodynamics of MDMA in a controlled study in healthy subjects. Pharmacogenet Genom 2016; 26: 397-401

30. Hysek CM, Liechti ME. Effects of MDMA alone and after pretreatement with reboxetine, duloxetine, clonidine, carvedilol, and doxazosin on pupillary light reflex. Psychopharmacology (Berl) 2012; 224: 363-376

31. Benziger DP, Miotto J, Grandy RP et al. A pharmacokinetic/pharmacodynamic study of controlled-release oxycodone. J Pain Symptom Manage 1997; 13: 75-82

32. Smith K, Hopp M, Mundin G et al. Single- and multiple-dose pharmacokinetic evaluation of oxycodone and naloxone in an opioid agonist/antagonist prolonged-release combination in healthy adult volunteers. Clin Ther 2008; 30: 2051-2068

33. Samer CF, Daali Y, Wagner M et al. Genetic polymorphisms and drug interactions modulating CYP2D6 and CYP3A activities have a major effect on oxycodone analgesic efficacy and safety. Br J Pharmacol 2010; 160: 919-930

34. Pauli-Magnus C, Hofmann U, Mikus G et al. Pharmacokinetics of morphine and its glucuronides following intravenous administration of morphine in patients undergoing continuous ambulatory peritoneal dialysis. Nephrol Dial Transplant 1999; 14: 903-909

35. Osborne R, Joel S, Grebenik K et al. The pharmacokinetics of morphine and morphine glucuronides in kidney failure. Clin Pharmacol Ther 1993; 54: 158-167

36. Portenoy RK, Foley KM, Stulman J et al. Plasma morphine and morphine6-glucuronide during chronic morphine therapy for cancer pain: plasma profiles, steady-state concentrations and the consequences of renal failure. Pain 1991; 47: 13-19

37. Raina R, Krishnappa V, Gupta M. Management of pain in end-stage renal disease patients: Short review. Hemodial Int 2018; 22: 290-296

38. Salili AR, Muller D, Skendaj R et al. Breakthrough pain associated with a reduction in serum buprenorphine concentration during dialysis. Clin Ther 2016; 38: 212-215

39. Zwisler ST, Enggaard TP, Noehr-Jensen L et al. The hypoalgesic effect of oxycodone in human experimental pain models in relation to the CYP2D6 oxidation polymorphism. Basic Clin Pharmacol Toxicol 2009; 104: 335-344

40. Heiskanen T, Olkkola KT, Kalso E. Effects of blocking CYP2D6 on the pharmacokinetics and pharmacodynamics of oxycodone. Clin Pharmacol Ther 1998; 64: 603-611

41. Zwisler ST, Enggaard TP, Mikkelsen S et al. Impact of the CYP2D6 genotype on post-operative intravenous oxycodone analgesia. Acta Anaesthesiol Scand 2010; 54: 232-240

Received: 31.5.2018; Editorial decision: 19.7.2018 